\section{Transparency regimes and management by content in global organizations. The case of institutional currency trading}

\author{
Karin Knorr Cetina and \\ Urs Bruegger
}

Karin Knorr Cetina and Urs Bruegger are both at the Faculty of Sociology, University of Bielefeld, Bielefeld, Germany.

\section{Abstract}

Argues that informational arrangement may make an organization less of a cumbersome machine by exteriorizing organizational processes on screen, making them transparent, witnessable and (reflexively) selfchanging. The platform organization addresses how some organizations - global investment banks engaged in institutional currency trading and big science collaborations engaged in high energy physics knowledge production - implement a transparency regime of information that extends to local and implicit knowledge. In other words, through being exteriorized, knowledge is kept current, alive and distributed in the respective organizations; to a significant degree, it is effectively precluded from becoming implicit and embodied in places and persons. Corresponds to a form of coordination that is content-driven rather than social authority based. "Management by contact" is a knowledge-enhancing, specialist activity closer to mediating and coaching than to "governing" and deciding.

Konstanzer Online-Publikations-System (KOPS) URN: http://nbn-resolving.de/urn:nbn:de:bsz:352-opus-81132 URL: http://kops.ub.uni-konstanz.de/volltexte/2009/8113/

\section{Introduction}

In this paper, we begin to develop an analysis of organizational principles manifest in organizations that are genuinely global, meaning that the activities they pursue span the globe and that they involve participation from countries and continents located in the three major time zones. Such organizations pose an obvious question, which is how activities stretched out globally can be coordinated across space and time. We will not seek an exhaustive answer to this question but instead focus on certain patterns and mechanisms, attempting at the same time to specify a distinctive type of organization. Some of these patterns, we think, mark an important shift in organizational logic. They contrast not only with models of bureaucracy based upon hierarchical mechanisms of social authority and control, but also in some respects with the idea of the network organization with which analysts have tried to capture recent changes in organizational form. Networks reflect social relations between (organizational) actors, and in this respect, they can plausibly be argued to underlie most if not all organizational activities, including the ones considered in this paper. Studies which propose that organizations have become more network-like generally, however, refer to something more specific; for example the replacement of centralized production with relational forms of contracting and cooperation and the decomposition of the firm into business units interacting with each other as independent centres (Powell et al., 1996; Stark, 1996, 2001; Castells, 1996; Uzzi, 1997). The notion of the networked firm has also been used as a metaphor for the kind of connection in the network, one characterized by a combination of informality, equality and commitment (DiMaggio, 2001, pp. 2,4; Uzzi, 1999). The organizational principles considered in this paper qualify under such headings, but we will nonetheless place the emphasis differently in seeking to determine

A preliminary version of this paper was given at the Workshop on "Heterarchies: the Organization of Diversity", Santa Fe Institute, Santa Fe, New Mexico, October 12 13, 2000. We thank David Stark, John Padgett, Walter Powell, Lucy Suchman, Susan Leigh Star, Gernot Grabher, Bruce Kogut and the other workshop participants for helpful discussions and suggestions. 
exactly how spatially dispersed organizations manage their affairs.

The basic insight which motivates our analysis is that informational arrangements, broadly construed, can lift weight off organizational configurations and the need for organizing, making it possible for organizations to be governed lightly and exterritorially. We thus claim that these arrangements account for organizations having the option of becoming flatter. They also clarify what flat management structures mean in some types of settings. The literature on the evolving characteristics of the business firm provides important evidence on the degree of coordination and authority exercised: both appear to have declined in the sense summarized by DiMaggio (2001, p. 8), since more employees can be managed effectively by fewer managers and horizontal teams have substantial discretion as to the work processes they use to achieve their goals. In this paper, we extend this analysis by showing that the type of information regime also matters; informational arrangements may make an organization less of a cumbersome machine by exteriorizing organizational processes, making them transparent, witnessable and (reflexively) self-changing. At its most pronounced, this type of information regime is based on electronic communication technologies, but it is not the technologies themselves which count: what matters is the implementation of these technologies as culturally specific accomplished social actions. The literature on the evolving characteristics of business firms is of course aware of the role of information technologies in inducing structural change. One of the reasons why some researchers are attracted to the network notion is because they see information technologies as the epitome of enterprises in a knowledge economy (e.g. Castells, 1996). Yet the literature also often gives short shrift to the concrete instantiation of these technologies, leaving out the details of exactly how some technologies are implemented. These details do matter, we maintain, in shaping the organizing process and organizational form, that is in determining whether relational ties bear the burden of organizing or whether this burden is carried by other structures. We argue in this paper that dispersed organizational forms may remain dispersed and network-like in terms of the geographical location of formal organizational components but may at the same time construct themselves as platformstructures when it comes to the practical implementation of organizational activities. A platform is understood here as a forum for exteriorizing organizational processes and activities. These bind participants to the platform and make the exteriorized available for reaction, re-entry, reproduction and change.

The exteriorization corresponds to a transparency regime of information that also extends to local and implicit knowledge: not only are the organizational activities of local places made visible and witnessable on the platform, but also the knowledge these places accumulate, the observations they make and experience they gather. In addressing a particular organizational format, the platform organization, we also address in this paper how some organizations - global investment banks engaged in institutional currency trading and big science collaborations engaged in high energy physics knowledge production - effectively navigate their way through a situation where knowledge is local and dispersed and resides with participants who are specialists, while the organization is global and needs to respond "to the whole picture", to a globally aggregated situation. The active learning process which ensues is non-hierarchical and inclusive within organizational boundaries; depending on whether the respective platforms are ongoing or sequential, learning is continuous or happens in stages. If we ignore such differences in timing we can perhaps say that through being exteriorized, knowledge is kept current, alive and distributed in the respective organizations; to a significant degree, it is effectively precluded from becoming implicit and interiorized in places and persons. What the platform-based transparency regime is aiming at is the accomplishment of a sort of distributed cognition, or if you wish, a collective consciousness about the state of affairs that is relevant to the organization. On the management side, this orientation corresponds to a form of coordination that is content-driven rather than social authority based. "Management by content" is a knowledge-enhancing, specialist activity closer to mediating and coaching than to "governing" and deciding.

\section{The organizations studied}

One distinction which runs through the analysis in this paper is that between embodied 
and disembodied organizational environments. In the first case material objects and their requirements of embodied labour lie at the centre of activities, while in the second case organizational business is conducted almost entirely in a symbolic space. The domain from which we derive our model of the transparency regime of information in a collective disembodied environment is that of foreign exchange markets as exemplified by interbank currency trading in large, global investment banks. We will briefly compare this case with that of the embodied environment of high energy physics laboratories in order to extend the range of applicability of the concepts of "a platform", "a transparency regime" and of "management by content" presented in this paper. We can also learn from the comparison that transparency is not simply a by-product of the sort of electronic environment in which interbank currency trading is conducted. The data presented in the currency trading study derive from a Swiss bank that has continuously been ranked as one of the top five or seven most profitable banks worldwide by reported foreign exchange trading revenues over recent years (FX Week, 1998)[1]. The bank's global presence involved, in 1999, a staff of 14,500 working in 60 offices in 30 countries on six continents. The foreign exchange markets studied have a specific global form, which is not based on the penetration of countries or individual behaviour but instead rests on the establishment of bridgehead centres of institutional trading in the financial hubs of the three major time zones: in New York, London and Tokyo, and, since the group to which the investment bank belongs is Swiss, in Zurich. Institutional investors in these regions are linked up with the global bank (henceforth GB1) through "open” or immediate access phone lines. Foreign exchange deals through these channels start in the order of several hundred thousand dollars per transaction, and go as high as a hundred million dollars and more. The deals are made by traders, financial managers, fund managers, central bankers and others who want to avert or hedge against adverse currency moves, who want to profit from expected currency moves, or who need currency to help them enter or exit transnational investments.

We will explore the organizing principles in use in the global investment bank against the backdrop of the embodied environment of a "big science" laboratory, the CERN in
Geneva, whose globally constructed experiments turn around the building and use of a massive material machine, a particle detector, that dwarfs human effort (Knorr Cetina, 1999, ch. 7,8). In size and duration, high energy physics ("HEP") experiments are the largest and longest contemporary experiments. About 200 physics institutes and 2,000 physicists are taking part in the ATLAS experiment now being installed at CERN in Geneva, the European Laboratory for Particle Physics jointly financed by European countries - an undertaking that will have lasted, when it ends, for about 25 years or the better part of the working life of a physicist. The physics institutes that form the ATLAS collaboration are located all over the world, with significant institutional participation coming from the USA, Europe and Japan not all that unlike financial markets. HEP experiments have not always been so large and global. They jumped in size to $15-20$ times their former average size only in the 1990s, for reasons having to do with the size of the detectors and collaborations needed to explore current energy regimes, and the unwillingness of governments to finance parallel efforts on several continents. Technically, laboratories build and run accelerators and colliders which provide the particle clashes that leave traces in detectors where they can be measured by physicists. Experiments build, run and harvest these detectors. Organizationally, experiments conduct "science" while laboratories provide the (infra)structure for carrying it out; experiments and laboratories are differently financed and constitute different administrative and legal units.

\section{An organization on screen}

We now turn to institutional currency trading, presenting its transparency regime in detail; in order to do so we will need to pay some attention to the concrete setting in which foreign exchange deals are made. About 200 traders engaged in stock, bond and currency trading worked on the floor in the global investment bank observed. Currency traders sit at "desks" consisting of a row of several (612) single desks. They have a range of technology at their disposal, most conspicuously up to five computer screens confronting each trader, displaying the 
market and serving to conduct trading. The thickly-layered screens provide the core of the market and most of the context. They come as close as one can get to delivering a standalone world that includes "everything" for its existence and continuation: at the centre, the actual dealing prices and incoming trading conversations; in a second circle the indicative prices, account information and some news (depending on the current market story), with further headlines and commentaries providing a third layer of information. The market has of course by no means always been on screen. Screens began to "appresent" (Husserl, 1960, sections 49-54) a dispersed and dissociated matrix of interactions and interests only in 1973, when the British news provider firm Reuters first launched the computerized foreign exchange system "Monitor", which became the basis for this electronic market. We choose the term appresentation to emphasize that the screens are not, in their core elements, representing a reality out there but are constitutive of it. The screens appresented the market only gradually, however, first providing nothing more than indicative prices and news. Actual dealing remained extraneous to screen activities and was conducted over the phone and telex until 1981, when dealing services also developed by Reuters went live (Read, 1992, pp.283ff.). Yet from the beginning, "Monitor" radically changed one aspect of dealing: it answered the question as to where the market was, i.e. what the prices of currencies were and who might be ready to deal. Before the market-on-screen, prices differed between places and had to be ascertained afresh for every deal through long and painful processes of phoning up banks and waiting for lines when going through operators for overseas calls. After the introduction of Monitor, prices suddenly became available globally to everyone connected by the system, in a market that functioned between countries and between continents. Before the market-on-screen, there existed dispersed networks of trading parties entertaining business relationships. After the introduction of the computerized screen quotes, "the market" acquired a presence and profile of its own, and its own temporal and other properties. The electronic programs and circuits which underlie this screen world assemble and implement on one platform the previously dispersed activities of different agents; of brokers and bookkeepers, of market-makers (traders) and analysts, of researchers and news agents. In a sense, the screen is a building site on which a whole economic and epistemological world is erected. It is not simply a "medium" for the transmission of other interactions.

\section{'... There are no more than three hierarchical levels immediately involved with spot trading...'}

If the screen is the building site for an economic world, it has also become a building site for organizational life. We have described the screen world of the market because the life on screen of the market appears to be taken, by participants, as a model for organizing the life of a trading unit. Consider what such a trading unit consists of: it is a formal subdivision of the global investment bank and a profit centre in its own right. Subdivisions relocated in four global cities: Zurich, London, New York and Tokyo. The global head of spot trading has his office in New York, even though Zurich, and not New York, has in the past been the most profitable spot trading location. The trading locations in the four cities are supervised by local heads, as a rule former traders who have been promoted to this position. There are no more than these three hierarchical levels immediately involved with spot trading. The option trading division is similarly organized, with the global head of option trading placed in London rather than New York. We thus have an organization that is spread out across the globe with absentee leaders of the higher level who visit the various units for several days two to four times a year. On such occasions, they attempt to get to know individual traders; they are also involved in bonus and pay decisions at the end of the year; evaluations of individual traders as well as hiring and firing decisions are made mainly by local heads of trading. Organizational tasks appear "light" despite large amounts of trading volume (a star trader had a daily trading volume of US\$1-2 billion when we started observations in 1995/96), and substantial profits made by the bank from currency trading (FX profits worldwide were approximately US $\$ 500$ million at the time). In fact, they are so light that local heads of trading spend most of their time participating 
in trading at the desks rather than in their offices.

This "lightness" of organizing has to do, we maintain, with the exteriorization of organizational activities and of local knowledge on screen. The exteriorized market on screen constitutes a platform that is visible to all connected to such screens worldwide. The bank's relevant centres and facilities are not only connected to other banks and trading facilities with whom they engage in transactions, but are also connected internally through elaborate "intranets" internal computer linkages that extend across the globe. This electronic infrastructure constitutes a network, but what we need to add to the network imagery is the idea of the screen, of the shared appresentation of organizational activities worldwide. Identical screens shared by traders and supervisors worldwide lay out organizational activities on one platform, allowing them to be performed on one common surface, and also offering knowledge a new non-local "home" in addition to the "locus" it may have in embodied persons and local centres. In many contexts, computer screens serve to increase the reach, the scope and the speed of communication, making it possible for more employees to be reached and managed more effectively than in face-to-face contact. But in contexts such as the present, screens serve not only as entrance ports to communication "channels" but as complex and multi-layered work-interfaces between participants. Such "screens" integrate the organization, reconstructing it on the platform they present. The platform is an additional space and regime apart from the embodied organizational components' geographical locations, a building block in the multiple construction of organizational reality (Stark, 1999).

\section{The informational transparency regime}

We now want to confront more directly one aspect of the platform described, the phenomenon that it is an informational arrangement that implies a politics of knowledge: the platform corresponds to a regime of transparency. The witnessability of activities - the laying open of activities in a public forum - lies at the heart of what we call a transparency regime. The regime rests on further components not yet discussed, such as bulletin boards, accounting programs, and the visual witnessability of embodied activities in each trading centre. First, on the most general level, supervisors can "witness" the activities of traders as members of their organization at the same time as they witness the market as it composes itself from traders' global activities. They can see not only the trading prices, other banks' indicative prices, the news and news analysis which are routinely displayed on screens, but also the trading conversations, information conversations and electronic broker deals of floor traders. The extent of this witnessability must be appreciated. If, for example, in the price finding process for an option deal the Zurich desk discusses the option with London, the bank's other option desks worldwide listen in on these conversations, as the head of option trading confirms in the following exchange:

KK: They listen (to these conversations)? They can (see them)?

SJ: (...) When you discuss something via the direct line with London then everyone worldwide hears it, which means, everyone can join the conversation. Just generally, they can join. If you have some relevant information, which the other two who discuss something don't have, then this information gets added (to the discussion), and (you say), hey, I heard about (this or the other option in the market) (etc.).

"Listening" and "hearing" in this report refer to the witnessing of conversations conducted on screen and the "direct line" means a conversational line on screen that remains open during working hours.

Consider witnessability in relation to the implicitness or explicitness of knowledge. Trading conversations, even those which do not involve "discussions" and information questions, are always at the same time information conversations. The fact that a currency is sold conveys information about potential market direction and underlying events; the price itself is information, and dealing conversations frequently contain, or are embedded in, direct information exchanges about markets. If this information is witnessable on screen, a significant portion of the relevant information would seem not to be implicit but to remain out in the open. This information becomes the property of everyone witnessing it; on the basis of the accessibility of information or the 
"experience" of events at least, it is no longer possible to draw any sharp distinctions between those who develop implicit knowledge and those who do not - all have access, and all experience the events. There are, however, certain kinds of information which derive not from screen activities but from local and regional contexts and contacts. For example, what the Ministry of Finance in Japan (which influences the policy of the Japanese Central Bank) might have on its mind is easier to assess, traders think, in Tokyo than in Zurich, thanks to information obtained from local contacts, from briefings, and from reading the local news and observing the local context. In the case studied, these observations did not "sediment" in the local centre and become the implicit knowledge of a place, or of individual traders. They were also made witnessable and globally available in the transparency regime described. How? Through bank-internal bulletin boards, a second component of the transparency regime described. Bulletin boards are shared electronic forums on which participants at various trading centres enter short confidential observations. A variety of such bank-internal bulletin boards of general ("FX ALL") and domain-specific interest (the boards "FX SPOT", "FX OPTIONS" and "FX SALES") have been implemented; they are accessible to the traders, salespersons, analysts and managers in the respective domain in the whole bank globally. The confidentiality of the information is important; bulletin boards are designed to exteriorize the most sensitive information:

RD: ... The most sensitive information should go there, the least sensitive should go out to customer, or internal contacts. I mean this is the holy grail!

Figure 1 provides an example of such bulletin board observations.

The advantage of bulletin boards, then, the boost they provide to transparency, is that they link distant trading places through the posted observations of what these places see locally, in their region of the world. But the advantage of bulletin boards also lies in the fact that supervisors, in watching market developments on such boards, become privy to traders' activities, and are able to judge them. The following assessment of the role of the bulletin board in determining the reputation of a trader in the bank, like the previous quote, comes from an experienced salesman on the floor:

RD: ...you know NN (global head) uses this as his (device?) to judge people (...). So if you don't put anything there at all you are in trouble, if you put something there which is useless or incorrect you are certainly in trouble and if he feels somebody is not doing their bit, he will say, "Richard, why haven't you given any input today?" or, "I really disagree".

KK: (question about feedback)

RD: Yeah, (you get) negative feedback not just from your boss, but (...) if you put something there that's stupid, you know there are probably 200 or 300 people, extremely intelligent people all around the world, looking at that. If 20 of them think that something is stupid they are going to tell you, "Don't be stupid, that's ridiculous, Richard". And if you can't disprove it everybody in the whole bank globally knows that you've done something stupid.

Third, managers have at their disposal not only the market and the actions of their traders as well as their traders' abilities and local knowledge, as captured by bulletin boards, but also traders' positions in the market: they see whether a trader is positioned "long" or "short" on a currency, and what his profits or losses are at a given point in time. They also see where a trader stands with respect to the daily trading limits he or she is given and with respect to his or her annual earning goals. Not only the activities, but also the traders themselves, as winners or losers on the market, are transparent to supervisors at any point in time. In a sense, traders are their own track record in this transparency regime. While bulletin boards provide (distant) supervisors with knowledge about local places and about the activeness and observational capabilities of local traders and salespersons - knowledge that would otherwise remain implicit - market positions and accounts disclose and track the "worth" of their employees for the bank in real money, potentially on a second-to-second basis (accounting periods are longer in options dealing). Transparency, then, extends to the financial performance of participants. It also extends, fourth, to the trading floor itself, which constitutes a further source of information for traders and supervisors - one that reaches more into the embodied side of things. Trading floors tend to be large rooms in which trading desks, screens and traders' embodied activities are fully in view of everyone present. This particular physical arrangement places the participants in the 


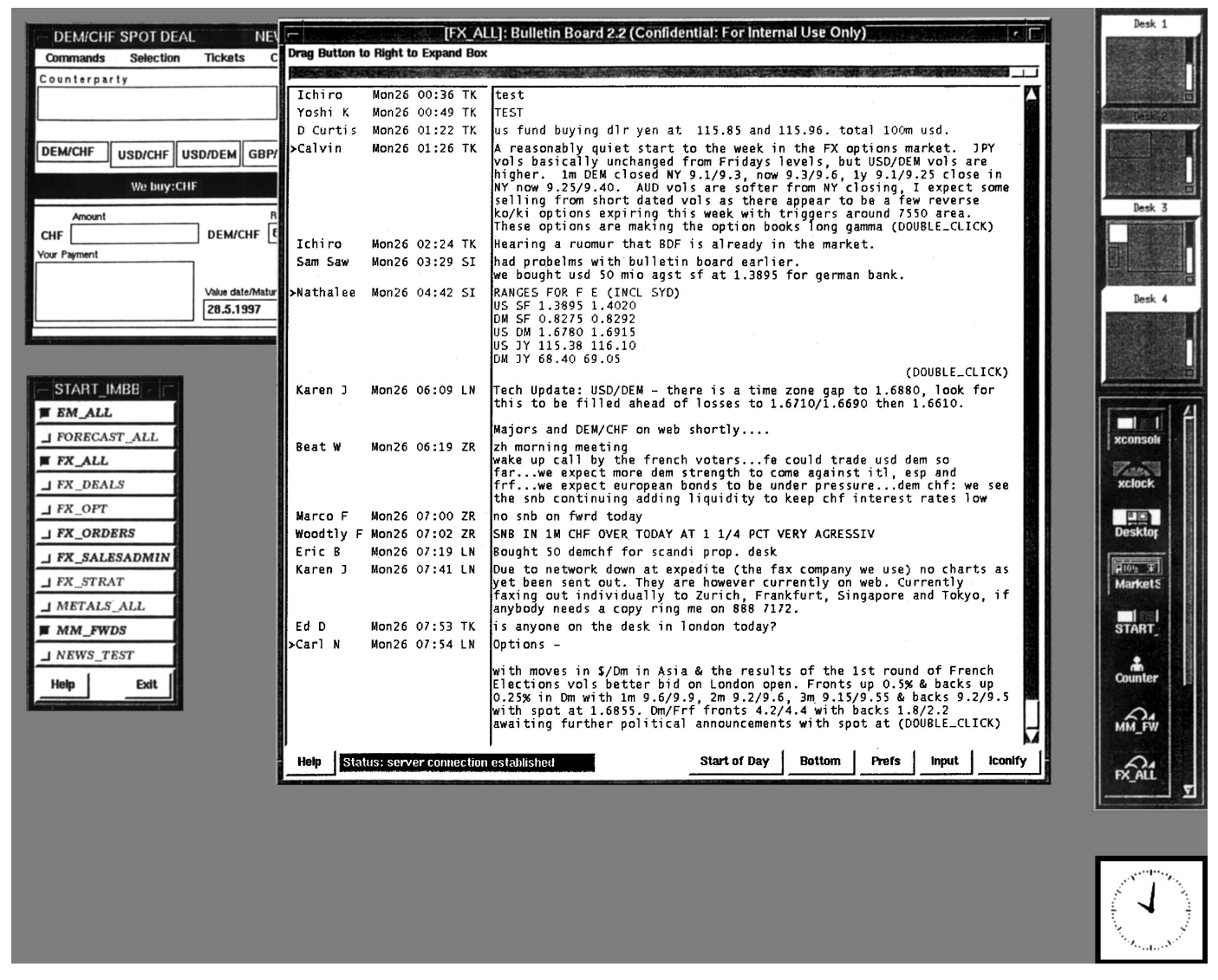

centre, so to speak, of their own mutual auditory and corner-of-the-eye visual attention. It enables traders who have their gaze riveted to their screens and their attention focussed on their own currency to remain aware of other currencies' and players' moves - as signalled by others' "response cries" (Goffman, 1981), jumps, gesticulations and loud requests for prices or for information. The trading floor is a fully transparent place (Bruegger, 1999, p. 285); its geography also allows local heads to remain "on track" regarding the performance and problems of their team, and regarding general market tendencies in other areas.

Finally, there are also recorded and written sources of transparency such as records of all phone conversations on the floor and transcripts of all trading conversations. These are not consulted routinely, but are available for inspection when misunderstandings arise or fraud etc. is suspected. As such records as well as the bulletin boards and other means of observation suggest, organizational

transparency in this area is not just a "natural side effect" of the electronic instantiation of global markets, although it is also that. The witnessed global settings also have an accomplished sense - some witnessability derives from conscious organizational decisions to enhance transparency, and of course witnessing must also be practised, as it is in the specific management style implemented in this area. Organizational decisions to enhance transparency are sometimes taken in the wake of historically contingent circumstances. The bulletin board, for example, was introduced only a few years ago, originally in one version, with the bank we studied priding itself on being the first to have this device at its disposal. It was then quickly expanded as its usefulness was recognized. Phone conversations were beginning to be recorded in response to irregularities in dealings on the international market, to protect the bank against misuse by traders. Dealing transcripts, which are now automatically produced, have their origins in the need for back-office clearings of transactions. Some components of performance tracking are part of trading, but others require special accounting programs which have been implemented. Accessibility to bulletin boards and trading conversations could be limited to supervisors or a few traders, but is not. In a sense, global 
investment units appear to have been reinventing themselves according to the model of the exteriorized market on screen and the transparency it provides. They have made use of similar principles to run the organization in ways based on intense observation and communication.

In concluding this section, we want to point to some features which distinguish organizational transparency of the kind considered here from the transparency implied by a related notion, that of the Panopticon. Michel Foucault (1977) used Jeremy Bentham's notion of Panopticon to propose a notion of modern power that is based on surveillance. Accordingly, a prison designed as a round space of several stories of inmate-cells with openings toward a central tower is an efficient surveillance arrangement: the inmates, confined to their cells, can be watched at all times by a single guard placed in the centre of the building. Foucault used the image of Panopticon as a metaphor for the way control can be exercised in the modern factory and for the way residents are kept under surveillance by modern territorial states. The transparency which results from this surveillance is clearly exclusionary and hierarchical. The lives disclosed are those of subordinates and subjects; power accrues to those who appropriate the information. This sort of transparency regime is also plainly a territorial regime: it rests either directly upon architectural design or upon the territorially bound power of nation states. To some degree, such boundaries also matter in the case of the transparency regime sustained by the symbolic platform of the screen: while that part of the platform that is "fed" by Reuters and other firms is shared by all trading institutions that pay the fees to obtain the information (virtually all trading units of major financial service organizations), bulletin boards, traders' deals and conversations are transparent only within a particular firm and trading domain (e.g. within the spot-trading unit). Within these organizational boundaries, however, the regime is ex-territorial, nonhierarchical and inclusionary rather than exclusionary: traders, too, have access to bulletin boards and other elements, and managers need not be local to share the information. Management effects derive not from access to but from the use of the information.

\section{Management by content}

How do managers use the information? As a springboard for this discussion, it is interesting to note that local heads and to a substantial degree also the global heads of trading units spend much of their time at trading desks, at and in the market. For example, the local head of spot trading in Zurich, who was presiding over the earning of an annual profit of roughly US $\$ 40$ million when we started our observations in 1995/96, spent about 80 per cent of his time at the trading desk according to his own assessment. He did this up to June 2000, when he left the bank. We hardly ever saw him in his glass cubicle office on the trading floor, which he placed at our disposal when we were there. Some supervisors, like the local head of options trading, engage in proprietary trading while at the desk (meaning they trade not for their own account like other traders but take positions for the bank), though the head of spot trading did not. He would sit next to what he called his key trader (a star trader handling the most important currency pair in Zurich, the Swiss franc against the dollar, and making the most money, roughly US $\$ 15$ million of the 40 million cited), observe the market, observe the star trader's and his other traders' positions and moves, and occasionally help traders out, meaning he would get prices when they needed them or take their spot when they took a break.

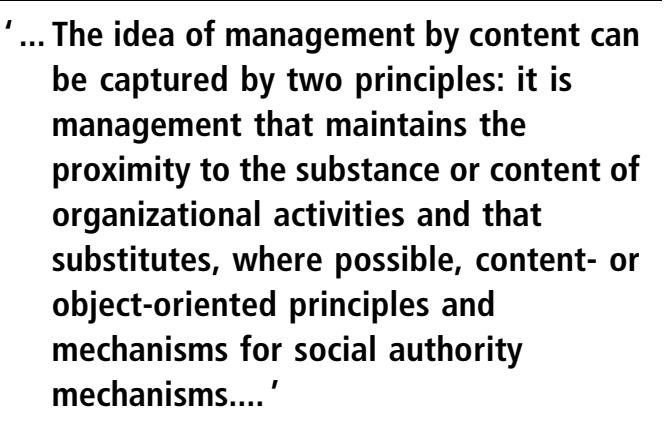

This participation by managers in floor-level activities, their full inclusion in and deliberate pursuit of floor level knowledge, is what underlies a particular management style which we call "management by content". The idea of management by content can be captured by two principles: it is management that maintains the proximity to the substance or content of organizational activities and that substitutes, where possible, content- or 
object-oriented principles and mechanisms for social authority mechanisms. The elaborate forms management by content can take will be illustrated in the last section of this paper, when we present the contrasting case of an embodied, scientific organization. Within the limits of the "light" management in the area observed, management by content means, first, the participation indicated, second, a form of mediating and coaching that is based on this participation, and third, the routinization of the flow of change.

What participation means in this context has been stated, but two points should be added. First, managers are also centrally located in the local face-to-face conversations of the trading "desks" they supervise and in the discourse of other units on the trading floor. Heads of trading speak to their traders in their office when such an action is required, but they mostly speak to them at their desks, moving between them and other units and local heads; they also confer with global heads several times a day on the phone. Graphically speaking, heads of trading are not the "top" of a unit, or its "spearhead" pointing forward, but centrally placed within it. Second, the closeness of managers to the market, their presence at the desk and their proprietary trading and "assistance-giving", allows them to maintain their expert status in the area they supervise. Thus managers are not only centrally placed but they remain "specialists", as indicated in the following description:

KK: Are they (the bosses) usually close to the market enough to even judge (the information)? RD: Oh, sure, yeah, yeah, yeah, completely, yeah. How it's done in (GB1), all the senior bosses are really as close to the market as I am, you can't get any closer! You don't have to trade but you watch all day. What does N.N. (global head) do when he is here, he sits at the desk like this. . and then he produces some management reports in between so it doesn't matter where he is globally, he can control everybody in the whole organization (...) so as long as he knows where the market is ( $\mathrm{He}$ also) works very long hours but all the senior bosses are like that, in (GB1) there is very much an ethos towards, uh, being a competent specialist boss who has gotten there through a meritocracy much more than it was at (GB1 before merger), where it was more of a managerial role, now it's much more of a specialization.

The notion of management by content is meant to invoke the image of a closeness to the substance of organizational activities that is equivalent to specialist knowledge. This status as a specialist underlies the second component of management by content in the present context, a style of management best circumscribed by "mediating" and "coaching". A mediator is someone who facilitates negotiations and, agreements between parties; someone who provides feedback, guidance and/ perhaps most importantly, emotional support. In baseball, football and other sports coaches train players, build up their confidence, and assign them to the right place. The heads of trading we saw were not occupied with training young traders become apprenticed to more experienced ones whom they assist before being allowed to take their own positions in the market - but they coached in other respects and mediated between traders and market, focussing particularly on the consequences of winning and losing in the market. A trading floor, as Abolafia has emphasized (1998, p. 10), "is not understood as a place to satisfice, footdrag or merely survive, as in other organizational settings. It is a place to win". One problem traders have is that they cannot win continually and must not lose their grip when they don't. It is in such situations that mediation and counselling become important, as the head of spot trading sees it:

First of all you have to manage them when their positions are bad. When they have good positions, they don't need anybody. Then they fly on clouds and think they are close to God. They can always deal with this. When things don't work out, then you have to manage them.

He also tells us what he means by this:

OK, I may occasionally say, "Let's close this position." But I try not to do that. Because then they lose confidence (...). They should be able to decide for themselves when to stop, they have their stoploss limits. But you can make them aware of certain things. If someone is negative on (currency pair), you can look at the chart and say, "OK, this is the point, if (the value of the currency) goes beyond that, we buy it back." They sometimes need a second opinion, such that they will be able to say, "OK, I close the position".

The star trader on the floor shares this view: A trader needs two things to be successful. Self confidence and support. If this is missing you may as well quit. I don't need anybody to congratulate me when I have earned fifty thousand Swiss francs. But when I am down, I need someone who tells me to go on.

Managers, then, coach traders back to winning when they have a losing streak, trying 
to build up their confidence slowly by advising them to take small positions, much as a counsellor would. They also coach traders when they have winning streaks, bringing them back to normal expectations when they think they are "Masters of the Universe" (Wolfe, 1988). They may mediate conflicts and put an end to the fights which sometimes arise between traders. One aspect of the mediating task is to find proper matches between traders and currencies, both of whose "characters" need to be aligned for trading to be successful. Thus managers distil character assessments from observing traders at work, and then try to fit "rogue" dealers to "rogue" currency pairs, while reserving currency pairs which need strategic thinking, like dollar-Swiss franc, for the "men" among the traders.

Matching is also part of a second set of tasks mediation involves, that of putting the right traders in the right places so that they form a good team, making as much money as possible for the bank and for themselves. For this purpose, one needs the right mix of "stars", "talents" and "reliable" traders with respect to a market and currency. The head of spot trading wanted the stars to hold the team together and build a name in the market; he needed the talents to replace the stars when they left and to rein them in somewhat, and he needed the reliable traders so that the stars could be stars and the talents talents:

There are risks related to people. If you have only one superstar and there is nothing around him the risk is too big, because if he leaves you have a problem. For this reason you have to diversify somewhat. You have to make sure you have a star, but the distance to the others (...)should not be too great. You also can't have three stars (on the floor).

The head of spot trading also wanted to make sure that the desk was free of burnt-out, riskaverse and deviant traders, of "loners" and of those who were simply unsuccessful. $\mathrm{He}$ considered this an easier task than making money by trading; hiring and firing decisions were up to him, and when traders are fired, they tend to have to clear their desk within a very short time (e.g. half an hour):

Before, I had to earn money in single currencies, and now I have to make sure that the whole team makes money. This is a bit simpler than before. I can simply exchange them (traders) when they are no good.

Mediating, then, also involves constructing a team in ways informed by what the "playing field" (the market) and the "portfolio" of traders one has already assembled looks like. It also includes rewarding, for which the main instrument is the bonus. Decisions about the overall bonus a unit earns were made in back and forth consultations between the local and the global head; the bonus depends on the overall earnings of the bank. The decisions about how to distribute the bonus among the traders on the floor were made by the local head. The decisions are made by roughly the middle of February and announced in March and are surrounded by tension and a heightened sense of drama. The event itself is specially staged: traders are asked to receive the information in person in the glass cubicle of the local head, and the bonus will be announced by the relevant managing director in New York who is "present" via a phone loudspeaker.

\section{... The currency markets considered do not fragment into different local or regional markets, but are globally integrated; they change in stage-like ways, though on a "nano" time scale....'}

There is one more issue having to do with the style of management which is important because it brings to the fore the processual characteristics of management by content. Elsewhere we have put forward a concept of financial markets as temporal and sequential processes, a view which stands in contrast to the received concept of the market as a place. To be sure, the "platform" in terms of which we described the market on screen comes close to a spatial concept of the market. The platform is, in a sense, a virtual space constructed electronically between participants; it allows them to act (almost) as if they were in one space. But on the other hand, it must also be seen that the platform changes continually, usually not remaining "the same" for even a fraction of a second. The processual nature of the market in this area can easily be glossed from price movements. Unlike the prices of the goods displayed in shopping malls and other spaces of buying and selling in our consumer societies, financial market prices are neither fixed nor stable or subject only to slow change. Prices are reset and refigured in every single market action, and their movement lies 
at the centre of winning or losing in trading. Since the refiguring of prices occurs on a global platform, meaning that in any given fraction of a second there is only one global price, this price influences and constrains the next, which is why the process can be characterized as sequential. The currency markets considered do not fragment into different local or regional markets, but are globally integrated; they change in stage-like ways, though on a "nano" time scale. In these markets, we can say, the flow of change is routinized; change is not something that has to be made to happen, it happens continually, on a fraction of a second to fraction of a second basis. Accordingly, for traders and heads of trading, learning about price and market changes is also a continuous process. For example, the specialist head who manages on a content-oriented basis must do so in step with a content that "flows". To manage at all, the coach in a game and the mediator in a negotiation need to stay abreast of the "game" and the episodes that develop. If the object is processual in nature, the leader who is able to give counsel in tricky situations can do so only if he or she has kept track of the development of this situation. Markets are "situated" with respect to time rather than to space, and the situation-adapted response they require appears to leave only two options: either one maintains the proximity to the object, tracking its every development continually across time, which permits the sort of learning of the substance of a development that management by content is about, or one does not maintain this proximity, and then had better leave things to traders - as they are quick to point out - and retreat to the executive floor. In the case observed, governance by content also means that the specific rhythms of the market are imported into the organization and govern the rhythms of the trading floor: as principles that arise from the content of the work they hold traders to certain schedules, governing their expectations and behaviour and ordering organizational life as well as to some degree their personal life. The market is the flow of price changes, but these changes are themselves punctuated by schedules for the release of economic data, by decision schedules of the Federal Reserve and the European Central Bank, and similar time frames. The spot market, like other markets, lurches whenever important economic data are released, and the spot trading floor lurches with it (see also Lewis, 1989, p. 59).

Schedules, and more generally time frames inherent in organizational objects that have a life of their own, are an important ordering force in a learning and track-keeping process. The resulting order appears "objective"; it is not imposed by social authority structures.

\section{A contrasting case: the materialized global organization}

We have now discussed an organization where the symbolic platform and the transparency of global markets appeared welded into an enhanced intraorganizational transparency regime and a management style that signal an intense involvement with knowledge, attempt to preclude its interiorization, and serve continually changing outcomes. We now want to consider, if only briefly, the contrasting case of the global organization of high energy physics collaborations and experiments - a case where the organization is not disembodied but materialized, and work is "tied down" by material installations and bulky machines. These machines, detectors and colliders, require substantial amounts of physical space (e.g. underground "rings" 30 miles in circumference) and of embodied labour (e.g. 2,000 physicists). Organizational form corresponds to this situation. On the most general level, the organization, CERN, is a global centre, located near Geneva, where the detectors, colliders and surrounding facilities are placed. The collaborations which build detectors and create physics results are formed from institutes located all over the world, as mentioned, but these collaborations, too, have their nucleus at CERN: CERN itself represents one institute among others in the collaboration. Given the location of this institute at the site of the detector and collider, the carefully selected manpower resources it has at its disposal and all the other advantages that accrue from being part of the centre, the role of CERN in collaborations of several hundred institutes is far greater than that of the other institutes. In terms of the language of world systems theory, we have a centre-periphery structure, with a global centre organization (CERN as a laboratory) aligned with global network organizations (the experiments/ 
collaborations) through the centres of the networks also being placed at CERN.

We will not focus on CERN as a laboratory in the following but on the organization of these global collaborations. We want to discuss the platform-like structures they generate along with their form of managing by content. All participants and physics institutes placed globally, and CERN, are of course electronically connected. At least some of the non-local physics institutes (which may be national laboratories) have high speed computers and their own sophisticated laboratory facilities at their disposal. Accordingly, much groundwork for the detector, as well as some program development, data processing, data analysis and simulation is done in these spots. There is much "shipping" of components (and of scientists) back and forth between institutes and between them and CERN.

\section{'... It is plain that platform-based transparency corresponds to the exteriorization of local knowledge and organizational process in financial trading...'}

At some point, however, most components need to be transferred to CERN, where the final instrument is assembled, the experimental runs take place, and initial data selection and analysis are conducted. Long before that point and in fact even before the beginning of an experiment and the emergence of a full blown collaboration, the centre is the place where "collaboration meetings" occur, 1-2 week long assemblies of experimental participants held 4-6 times a year with the goal of bringing together all physicists actively doing work in an experiment (about half of those who are official members). Intermittently, many institute members from outside institutes will visit the centre and work there for periods of weeks, months or years, while being paid by their home institution. Coordination in this global context is a matter of electronic (email) communication which physicists have long used, but it is also a matter of extensive embodied visits from outside institutes to the centre.

The centre itself can be seen as a kind of platform; it provides a forum for meetings and discussion attracting physicists to the place where the main action is. But the most direct instantiations of a platform are the meetings themselves - they are full assemblies not only of collaboration members but also of experimental objects: the detector, the physics analysis, the computer simulations, the particles, etc. are visible and witnessable at these meetings in their effective current states, however preliminary these states may be. At the meetings, the state of the experiment is summarized and displayed and in fact made transparent. Transparency accrues from the specific sequential schedule of such meetings: the most narrowly focussed working groups meet on the first days of a collaboration week, each member reporting on the "status" of the work he or she has been focussing on since the last report. What then follows are larger subgroup and group meetings into which the more narrowly focussed results flow and where these results are summarized, highlighted and integrated. Plenary meetings and an institute meeting which takes financial decisions and approves new members and detector designs are placed at the end of such weeks. As the meetings grow larger in the course of the week, the "status reports" from earlier meetings add up, providing more allencompassing pictures of the state of the experiment and the future requirements which flow from this state. Note that with this sequential meeting structure, the main points of early status reports are routinely repeated several times in the later reports. The sequential order suggests a passing on of knowledge and technical displays from the expert group where the responsibility lies to wider and wider circles that take note of the details and play them back - through discussions, questions and comments. The intention and to some degree also the result of the sequential meeting structure is that at the end of the week(s) the state of an experiment that is built from globally dispersed knowledge efforts is made fully transparent and every member of the collaboration is fully aware of that state.

Collaboration meetings come close to general assemblies in political institutions, with some differences: first, it is not just heads or "delegates" of dispersed institutes who attend the meetings, though the presence of institute heads is desired, but also the physicists and others who do the actual work, including post docs and students. Second, it is not decisions taken at the end which are the 
most important, but the appresentation of experimental components - the exteriorization of the full state of an experiment and the bringing to attention of this exteriorized state to working members, as indicated. Though some of the decisions of the institute board indicated are important, they are placed at the end so as to be fully informed by the state of affairs laid bare, and by the "sense of the meeting" as it appears in plenaries. Third, the state of things is documented on visual records which are accessible to everyone - these records are simply copies of the transparencies physicists use in their status reports. Thus the collaboration has available all the details of knowledge as presented by the experts with whom the responsibility lies, not final public statements. It is plain that the sort of platform-based transparency which ensues corresponds to the exteriorization of local knowledge and organizational processes in financial trading. It is also plain that we are not just seeing a side effect of electronic connections, but an embodied transparency regime deliberately created and normatively sanctioned to forge global coordination.

The meeting platform and the transparency it brings about is a component of the contentbased management style in this area, which we can summarize while illustrating at the same time the collectivism and community structure of these experiments. HEP experiments differ from financial trading in that they need continuous cooperation to bring about any of the scientific results they pursue. As illustrated elsewhere (Knorr Cetina, 1999, ch.7), they have ways of forging this cooperation by limiting and subduing individual agency, while at the same time enhancing collective roles. The full exteriorization of processes during meetings signals an intense involvement with the content of experimental states, but it serves at the same time the creation of a collective consciousness about this state: an uninterrupted hum of self-knowledge in which all efforts are anchored and from which new lines of work follow. A collective consciousness, like an individual consciousness, is also a moral force. This, we think, sustains the voluntarism of the experiment observed, a form of selforganization where management by content intersects with a communal attitude of individuals taking responsibility for the whole.
The voluntarism can be illustrated by physicists coming forward and volunteering for work that needs to be accomplished. With everyone in the know about where the gaps are in an experimental effort that they all want to succeed, everyone is called upon to help close the gaps. Voluntarism, then, is a form of self-organization that content-based management can bring forth and rely on. The management style is also illustrated by leaders' involvement. As in the case of financial trading, leaders have attempted until now to remain specialists who carry out experimental tasks in addition to their spokesperson responsibilities. They have also maintained a central status in the discourse of these organizations, being present at all subgroup and group and plenary meetings, being central in electronic exchanges, and being the ones who act as interfaces with CERN as a laboratory and with financing institutions in participating countries.

Management by content is a notion which also suggests that object-centred principles of coordination may be deliberately substituted for social authority mechanisms in some areas, in ways that ship authority based "political" decisions out, placing them beyond the boundaries of an organization. One illustration of this is decision deferrals in cases of conflict over technological choices which occur routinely at the beginning of HEP experiments and may interfere with collaboration-forming. Experiments need all the participation of physics institutes they can get for the money and technical skills these institutes bring; but they must at the same time sift through and sort out some of the technologies in which institutes have investments, in order to build a coherent detector and working experiment. In the experiment observed these decisions were often delayed for several years, as a way of buying the time to test, develop and unfold the technologies further until "the truth would come out" (Gilbert and Mulkay, 1984, pp. 90ff.), that is, the "better" choice would become obvious. This process of nudging decisions into obviousness so that they will in the end not have to be taken relies on the level of content, or if you will the object side, to impose decisions on the social world. But the contests of unfolding which ensued among competing groups did not simply bring forth this truth. The technologies winning in the end were also successful because the winning 
group had more technical, financial or other support, because a bigger and more sophisticated home laboratory could make things work, or because they had a "head start" and could mobilize uncommitted physicists for their support. The unfolding strategy only seals over the "politics" of collaboration-forming. It does not eliminate strategic activities on the part of interested groups and individuals, but it mutes them, waits them out, attacks them from the rear through object-centred data. It is nonetheless a content-level strategy. When technical decisions are unclear but are made, they are made on the basis of the social authority of someone who has the power to decide. The insistence on unfoldings of technologies and decision delays by the management were an attempt to place such "non-objective" means of coordination (those not flowing from the object, the technology) beyond the boundaries of the organization and of its responsibility.

\section{Concluding remarks}

Management by content is a knowledgebased strategy of coordination geared to the "expert" status of participants. It is also geared, we argue, to bringing about a transition from dispersed and fragmented local knowledge to distributed knowledge, to knowledge shared by participants and locales (trading floors, physics departments) that are globally spread out in space. We have interpreted the informational transparency regime in which this management style is anchored as a way to preclude knowledge from remaining local and from becoming implicit. In institutional currency trading, the exteriorization of knowledge we have described relied, significantly enough, not only on shared screens and trading systems but also on specifically installed bulletin boards and tracking routines serving as conduits for the relevant information. In a sense, the integration and accumulation of knowledge that individuals achieve through embodied processing when they develop "implicit" knowledge is achieved here through such conduits, with the difference that the information remains publicly available within organizational boundaries on the common surface of the screen. In high energy physics, exteriorization was more laboriously achieved through physical meetings of participants at the global centre, CERN, through the special format of sequential meetings and through discourse formats, such as "status reports". Implicit knowledge, it would appear from these cases, is not only a component of all human information processing but is itself an information regime that flowers in the absence of the transparency mechanisms and management style described. Perhaps individuals only become experts through acquiring implicit knowledge. But organizations are collective frameworks, and they appear to exercise expertise also through informational arrangements that exteriorize knowledge and preclude knowledge sedimentation.

\section{Note}

1 The study of financial trading is based on one year of continuous participant observation on the trading floor of the investment bank at the location of the headquarters of the banking group in Zurich, and ten short periods of focussed observation of three days to one week over a period of three years. The data set also includes 81 qualitative interviews of approximately one and a half hours with traders, salespeople and analysts at the bank, documentary material and approximately 1,000 trading transcripts collected during the various stays. These data have been evaluated by means of selective interviews with members of other banks and a series of interviews with the main supplier of the electronic trading systems and information packages investment banks use, Reuters. The study is embedded in a larger effort also involving the investigation of the history of financial markets (Preda, 2000), analysts in large banks' research departments (see Mars, 1998), the analysis of financial documents and the investigation of what we call "global microstructures" (see Bruegger and Knorr Cetina, forthcoming). The design and results of the study of high energy physics conducted between 1987 and 1997 have been published (Knorr Cetina, 1999, particularly relevant here chs.1,7,8). The study is embedded in a more extensive undertaking to investigate contemporary knowledge cultures.

\section{References}

Abolafia, M.Y. (1998), "Opportunism and hyperrationality: the social construction of economic man on Wall Street", unpublished manuscript.

Bruegger, U. (1999), "Wie handeln Handler? Aketuere der Gloablisierung", unpublished PhD Dissertation, University of St. Gallen, Switzerland. 
Bruegger, U. and Knorr Cetina, K. (forthcoming), "Global microstructures: the interaction practices of financial market", American Journal of Sociology.

Castells, M. (1996), The Rise of the Network Society. Vol. 1: The Information Age: Economy, Society and Culture, University of California Press, Berkeley, CA.

DiMaggio, P. (Ed.) (2001), The 21st Century Firm, Princeton University Press, Princeton, NJ.

Foucault, M. (1977), Discipline and Punish, Random House, New York, NY.

FX Week (1998), Vol. 9 No. 22, June.

Gilbert, N. and Mulkay, M. (1984), Opening Pandora's Box: A Sociological Analysis of Scientists' Discourse, Cambridge University Press, Cambridge.

Goffman, E. (1981), "Response cries", in Forms of Talk, University of Pennsylvania Press, Philadelphia, PA.

Husserl, E. (1960), Cartesian Mediations (English translation by D. Cairns), Nijhoff, The Hague.

Knorr Cetina, K. (1999), Epistemic Cultures. How the Sciences Make Knowledge, Harvard University Press, Cambridge, MA.

Lewis, M. (1989), Liar's Poker, Coronet Books, London.

Mars, F. (1998), "Wir sind alle seher, Die Praxis der Aktenanalyse". Unpublished dissertation, Faculty of Sociology, University of Bielefeld.

Powell, W.W., Koput, K.W. and Smith-Doerr, L. (1996), "Interoganizational collaboration and the locus of innovation: networks of learning in biotechnology", Administrative Science Quarterly, Vol. 21,

pp. 116-45.

Preda, A. (2000), "Financial knowledge and the 'Science of the Market' in England and France in the 19th Century", forthcoming in Wagener, H.-J. and Rottenburg, R. (Eds), Facts and Figures. Economic Practices and their Rhetorical Form, Metropolis, Marburg.

Read, D. (1992), The Power of News. The History of Reuters, Oxford University Press, Oxford.

Stark, D. (1996), "Recombinant property in East European capitalism", American Journal of Sociology, Vol. 101, pp. 993-1027.

Stark, D. (1999), "Heterarchy. Distributing authority and organizing diversity", in Clippinger III, J.H. (Ed.), The Biology of Business, Jossey Bass, San Francisco, CA.

Uzzi, B. (1997), "Social structure and competition in interfirm networks: the paradox of embeddedness", Administration Science Quarterly, Vol. 42, pp. 35-67.

Uzzi, B. (1999), "Embeddedness in the making of financial capital: how social relations and network benefit firms seeking financing", American Sociological Review, Vol. 64, pp. 481-505.

Wolfe, T. (1988), The Bonfire of Vanities, Pan Books Ltd, London. 